\title{
Predicting Student Persistence: Pre-Entry Attributes that Lead to Success in a Collegiate Flight Program
}

\author{
Elizabeth Bjerke and Margaret Healy \\ University of North Dakota
}

\begin{abstract}
The purpose of this study was to examine student pre-entry attributes to predict student persistence and academic success in a professional flight program. The data set constructed for this study was drawn from a sample of 390 full-time, first-time students enrolled at a University, with Commercial Aviation as their declared academic major at the time of entry. The data examined the students' academic progress for the first year to the second year of enrollment. Pre-existing data were gathered from each student's institutional record and financial aid record. Multiple regression analysis was used to calculate the degree to which pre-entry attributes predicted student persistence and academic success. The study found significant relationships between pre-entry attributes in determining student persistence and academic success. Pre-entry attributes accounted for $9.6 \%$ of the variance in persistence, and $32.3 \%$ of the variance in academic success.
\end{abstract}

\section{INTRODUCTION}

Given that more students depart from their initial institution of higher education, than graduate (Tinto, 1993), the study of student persistence has been popular in higher education literature for over a half of century (Pantages \& Creedon, 1978; Metz, 2005). Despite the vast amount of research and attention placed on the issue of student persistence, still more than a quarter of the students who enter four-year institutions leave after their first year of study (Braxton, 2000). This perplexing phenomenon has become known as the "departure puzzle" (Braxton, 2000). When a student decides not to persist at a particular institution, not only is the individual student affected, but the university is also impacted by the loss. A thorough understanding of all factors related to student persistence is necessary for individual student success and institutional effectiveness.

In their synthesis of over three decades of higher education research, Pascarella and Terenzini (1991, 2005) noted that numerous theoretical frameworks (eg. Spady, 1970; Tinto, 1975; Bean, 1980) have been developed to help guide and focus inquiry in the study of student persistence and the departure puzzle. Acknowledging the growing acceptance of the importance of student retention, Tinto (1993) describes an explosion of research and policy reports that have been written in order to seek a better understanding of the forces that shape student persistence.

The benefits received by students who persist to graduation are numerous. According to the United States Census Bureau (2007), the average income across all disciplines for an individual who has at least a bachelor's degree is nearly twice as much as an individual who only has a high school diploma. Besides economic gains, Pascarella and Terenzini (2005) in their meta-analysis of more than three decades worth of research cite numerous studies which demonstrate cognitive and social ways in which students who attend college are benefited.

Some students attend college with very specific professional and career goals in mind that can only be attained by receiving the education and certification at a collegiate level. For example, a student who wishes to become a medical doctor would have to graduate from an accredited medical school and pass 
the national board exam for their specialty. Many other professional programs have similar requirements. Students who wish to become professional pilots and fly for a major airline, the subjects of this study, must meet certification requirements specified by the Federal Aviation Administration (FAA) as well as hold a four-year degree.

\section{REVIEW OF LITERATURE}

In an analysis of early literature and research on student persistence, Spady (1970) found that most studies were merely descriptive and lacked a theoretical framework that could be tested. Spady (1970) then developed one of the first theoretically based models of student persistence by applying Durkheim's (1951) theory of suicide and comparing it to the decision to withdraw from higher education. A student's decision to drop out of school is by no means as severe or permanent as one's decision to end their own life; however, Spady (1970) argued that this sociological theory proved a "fruitful vehicle for summarizing a large proportion of current research, and focusing future attention on the interaction between student attributes and the influences, expectations, and demands imposed by various sources in the university system" (p. 64).

To further elaborate on student departure, Tinto (1975) used Spady's (1970) model as a base and defined other variables consistent with the literature. Even in Tinto's (1975) early conceptual model of student departure he argues that the departure decision is a longitudinal process that must be analyzed in that manner. He further defined his model in a book where he incorporated social anthropology work of Van Gennep (1960), particularly his rites of passage (Tinto, 1993). By using aspects from both Durkheim's (1951) theory of suicide and Van Gennep's (1960) rites of passage, Tinto (1993) proposed a longitudinal model of institutional departure that consists of six sub-sections: pre-entry attributes, initial goals and commitments, institutional experiences, integration, goals and commitments after time, and departure outcome. These six sections run on a continuum of time, and are also influenced by the external community in which a student interacts. Figure 1 illustrates Tinto's (1993) model of student departure.

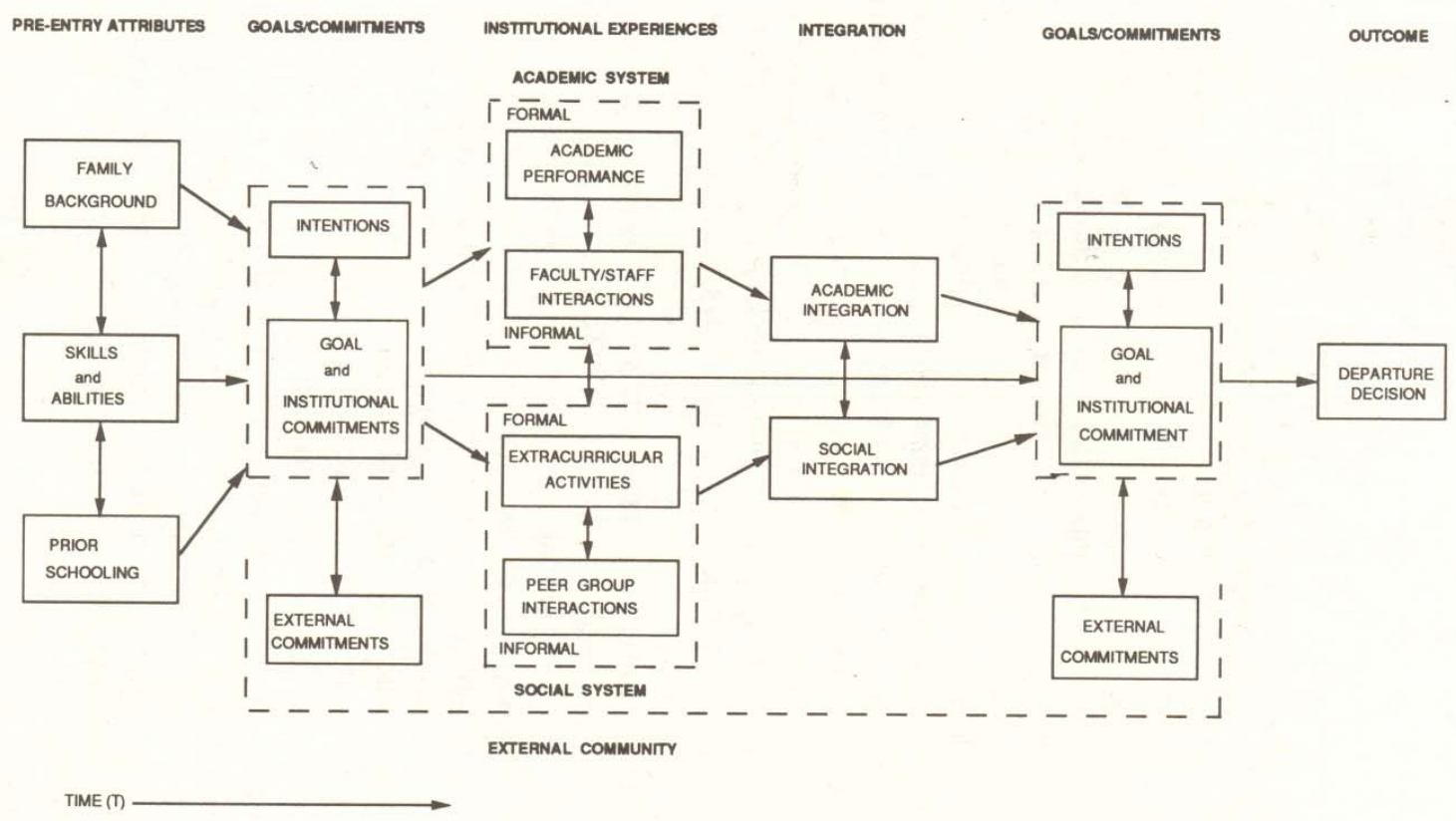

Figure 1. A longitudinal model of institutional departure (Tinto, 1993) 
Less than half of the students who initially pursue higher education graduate from their first institution (Tinto, 1993). Given the increase in need for aviation flying professionals (Ott, 2006), and the apparent decline of interested student pilots (FAA, 2007), it is imperative that the students who initially indicate an interest in the field and have the requisite aptitudes successfully complete their degrees. Although few areas of study in higher education literature receive as much attention as student retention (Tinto, 1998), in regards to student persistence in aviation, little research exists that is focused on aviation education.

As a means to study aviation retention issues, Luedtke and Papazafiropoulos (1996) created a survey that was administered to current students, former students and alumni of one aviation program. Despite the three groups of subjects used, the sample size was relatively small, making generalizations to other programs very difficult from the results. A study conducted by Beckman and Barber (2007) attempted to analyze the factors that cause students to initially declare the professional flight major but change majors prior to completion. This research took on a unique approach in that it surveyed students just prior to graduation and asked them to reflect on when they changed majors and recount the reason for the switch. The data indicated the largest group of students did switch from professional flight to one of the other aviation majors. It was found that students stated the reason for the switch was one of three primary reasons: financial constraints, time constraints and future job prospects (Beckman \& Barber, 2007). The authors posit that students initially choose the professional flight major because of the highly visible career track of a professional pilot, and that students discover more about the aviation industry while enrolled in aviation classes that causes them to change focus from flight to one of the other majors (Beckman \& Barber, 2007).

This study focused on pre-entry attributes, the characteristics that a student brings with them to the institution prior to enrolling. It includes constructs such as family background, skills, abilities and prior schooling. The first set of goals and commitments is used to measure the student's intentions and dispositions prior to beginning their advanced education (Tinto, 1993). It attempts to quantify how committed the individual is to attaining their degree as well as their level of commitment to that specific institution in which they first enrolled.

Pre-entry attributes have been found to have a direct and indirect effect on student persistence and academic success (Elkins, Braxton, \& James, 2000; Berger \& Milem, 1999; Caison, 2007). The pre-entry characteristics most frequently cited in the persistence literature include gender, academic achievement as measured by high school rank and/or grade point average, and academic aptitude as measured by ACT and SAT scores.

Many researchers use gender as a variable when studying its effect on student persistence (Magio, White, Molstad, \& Kher, 2005; Strauss \& Volkwein, 2004; Braxton, Milem, \& Sullivan, 2000). Gender is often found to have no significant relationship to student persistence (Herzog, 2005; Titus, 2004; Szafran, 2001; Murtaugh, Burns, \& Schuster, 1999). However, gender may play an even more crucial role as a pre-entry attribute when analyzed within the context of student retention within a male dominated field of study such as aviation. In a multi-institutional study of engineering programs and persistence, gender was found to have significance in five of the eight institutions studied (Zhang, Anderson, Ohland, Carter, \& Thorndyke, 2002).

There are two main ways in which researchers account for high school academic achievement: high school rank and high school grade point average. Researchers who utilize the class rank variable (Allen, 1999; Kahn \& Nauta, 2001; Pascarella \& Terenzini, 1980; Szafran, 2001) have found that it significantly correlates to student academic performance in college, thus it helps in predicting student persistence patterns. Murtaugh et al. (1999) found a decrease in attrition with increases in high school grade point 
average. Murtaugh et al. (1999) also state that there exists a "superior predictive value of high school GPA over SAT scores" (p. 369).

Many universities assess academic aptitude by using student scores on either the Scholastic Aptitude Test (SAT) or the American College Test (ACT) when granting admission into their institutions. This pre-entry variable has proven to help predict student success and persistence (St. John, Hu, Simmons \& Musobo, 2001; Maggio et al., 2005; Caison, 2007). Depending on the predominant test that students present at an individual college or university, the researcher either convert ACT to SAT (Szafran, 2001; Braxton et al., 2000) or SAT to ACT scores (Leuwerke, Robbins, Sawyer \& Hovland, 2004). Researchers have also broken down the composite ACT or SAT score and analyzed the effect of the math and verbal scores on student achievement and persistence. Leuwerke et al. (2004) found that engineering students with higher ACT math scores were more likely to stay in the program. Likewise, Zhang et al. (2002) found that higher verbal SAT scores were more likely to result in student departure from an engineering program. When analyzing major specific retention it is important to use all three aptitude scores in the process.

The purpose of this study was to examine student persistence in a professional flight program. Individuals seeking a career as a professional pilot with an air carrier are required to hold four-year degrees for most airlines, thus it is imperative that students who have the initial goal and commitment to pursue an academic major in flight are successful in completing the requirements. This research is focused on determining which pre-entry attributes can best be used to predict student persistence and academic success. The research questions are derived using a framework based on Tinto's (1993) interactionalist theory of student departure.

1. What is the relationship between a student's pre-entry attributes and persistence?

2. What is the relationship between a student's pre-entry attributes and academic success as measured in cumulative grade point average?

\section{METHODOLOGY}

\section{Setting}

This study was conducted with students enrolled in a public, four-year, research-intensive university. During the Fall of 2007, there were 12,559 students enrolled in one of the 193 fields of study offered at the university. These fields of study are divided into 10 main academic divisions and range from baccalaureate to doctoral degrees. The Department of Aviation currently offers four Bachelor of Science in Aeronautics degrees: Commercial Aviation, Air Traffic Control, Flight Education and Aviation Systems Management. The department also works closely with the College of Business to offer two Bachelors in Business Administration degrees: Aviation Management and Airport Management.

Commercial Aviation is the largest aviation major at the university and consistently accounts for over $60 \%$ of all aviation majors. This degree prepares students for careers as professional pilots in either an airline or corporate setting. The Commercial Aviation degree has been accredited by the Aviation Accreditation Board International since the accrediting body's inception in 1992.

\section{Participants}

Two cohorts of students comprise the sample for this study. Each cohort consists of first time, full time freshman enrolled as Commercial Aviation students. One cohort began in the Fall of 2006, the other in the Fall of 2007. The reason for utilizing two sets of incoming students was to ensure a large enough sample size. 


\section{Data Collection}

The data used in this study were obtained from two existing data sets: institutional academic records and financial aid records. The Office of Institutional Research provided the pre-entry attributes and academic record information from university records. The study utilizes a quantitative approach to predict student persistence and academic achievement. The dependent variables in this study include student persistence in the spring and following fall semester, and academic achievement measured by the term grade point average.

Pre-entry attributes collected on each student included the following variables: gender; age; ethnicity; high school grade point average; ACT scores broken down by composite, math sub score and verbal sub score; region of high school attendance; adjusted gross income; parental level of education and admitted credit hours. These pre-entry characteristic variables are consistent with previous retention research. Table 1 presents the pre-entry variables used in this study.

Table 1. Pre-entry Attribute Variable List

\begin{tabular}{lll}
\hline Variable Name & Variable Description & Source \\
\hline GENDER & Gender & Institutional Record \\
AGE & Age of student when enrolled & Institutional Record \\
ETHN & Ethnicity & Institutional Record \\
HSGPA & High School Grade Point Average & Institutional Record \\
ACTC & Composite ACT Score & Institutional Record \\
ACTM & Math ACT Score & Institutional Record \\
ACTV & Verbal ACT Score & Institutional Record \\
REGION & Region of High School & Institutional Record \\
INCOME & Adjusted Gross Income & Institutional Record \\
DADEDU & Father's Education Level & FAFSA \\
MOMEDU & Mother's Education Level & FAFSA \\
ADMCH & Admitted Credit Hours & FAFSA \\
\hline
\end{tabular}

\section{Procedures}

Once the dataset was complete it was imported into the Statistical Package for the Social Sciences (SPSS) version 16.0. The initial analysis of the data was purely descriptive. Frequencies were reported for each pre-entry attribute. Next, means and standard deviations for independent variables were computed. Since there were numerous variables used in this study, each research question was initially examined by looking at the correlations between the independent and dependent variables. A correlation is a single number that describes the degree of relationship between two variables (Trochim, 2005). The significance for this study was set at the .05 level.

Next, multiple regression analysis was used to answer the research questions. Multiple regression analysis is used to develop a statistical model for predicting the value of a dependent variable (persistence 
and academic success) based on numerous independent (pre-entry attributes) variables (Berenson, Levine, \& Krehbiel, 2002). Initially, all independent variables were inserted into the regression analysis by using the enter method. This method enters in all independent variables regardless of significant contributions (Mertler \& Vannatta, 2005). The second step entered the same set of variables using the stepwise forward method. The stepwise forward method enters independent variables one at a time into the model based on the magnitude of contribution to the overall prediction (Mertler \& Vannatta, 2005). The process stops when the inclusion of another variable does not have a significant effect on the overall prediction. Due to the nature of the variables used in this study, it was decided to replace missing values with the mean.

\section{FINDINGS}

The sample for this study was two cohorts of entering first-time, full-time students to the university with Commercial Aviation as their declared major during the Fall of 2006 and the Fall of 2007. The reason for using two cohorts was not to run comparisons between the groups, but to get a larger more significant total sample size. The sample includes 390 students who met these criteria. Demographic information about this sample is presented in Table 2.

Table 2. Demographic Information on Gender, Age, and Ethnicity $(N=390)$

\begin{tabular}{lll}
\hline Characteristics & $\mathbf{N}$ & $\mathbf{\%}$ \\
\hline Gender & & \\
$\quad$ Male & 340 & 87.2 \\
$\quad$ Female & 50 & 12.8 \\
Age & & \\
$\quad 322$ & 82.6 \\
18 and younger & 62 & 15.9 \\
20 and older & 6 & 1.5 \\
Ethnicity & & \\
$\quad$ White & 345 & 88.5 \\
$\quad$ Hispanic & 8 & 2.8 \\
$\quad$ Asian, Pacific Islands & 5 & 2.1 \\
$\quad$ Non-resident, alien & 4 & 1.3 \\
$\quad$ American Indian & 2 & 1.0 \\
$\quad$ Black & 15 & 0.5 \\
$\quad$ Not Reported & & 3.8 \\
\hline
\end{tabular}

Of the sample, there were 340 male students (87.2\%), and 50 female students (12.8\%). The age of the sample at the time of entry ranged from a low of 17 to a high of 29 . The mean age for the sample was 18.7 with a standard deviation of 0.9 . The majority $(88.5 \%)$ of the sample were White, non-Hispanic with the remaining sample being represented by Hispanic (2.8\%), Asian, Pacific Islands $(2.1 \%)$, non-resident alien (1.3\%), American Indian (1.0\%), Alaskan (1.0\%), Black $(0.5 \%)$, and not reported $(3.8 \%)$. Due to the lack of variability in ethnic make-up, the sample was dichotomized to White and non-White for further analysis.

The frequencies in Table 3 depict the student's academic achievements in high school for the sample. The listing includes high school grade point average, ACT composite scores, ACT math scores, ACT verbal scores and how many college credit hours they had earned when admitted to the university. The high school grade point average is depicted on a 4.00 scale with the low of 2.27 to a high of 4.00 with 40 
records $(10.3 \%)$ missing this variable. The mean high school grade point average for the sample was 3.27 with a standard deviation of .44. The ACT composite score ranged from a low of 12 to a high of 33, the mean score was 23.53 with a standard deviation of 3.24. The ACT composite score was not available for 80 students $(20.5 \%)$. The ACT math score had a range of 16 to 35 with the mean of 24.0 with a standard deviation of 3.74, while the ACT verbal score had a range of 10 to 35 with a mean of 22.2 and standard deviation of 4.40. Both the ACT math and verbal scores were missing from $100(25.6 \%)$ of the records. The majority (56.7\%) of the students were admitted without any prior college credits, however 99 students $(25.4 \%)$ did have up to 10 credits at the time of enrollment, 40 students $(10.2 \%)$ had between 11 20 credits at the time of enrollment, and 30 students $(7.7 \%)$ had more than 20 credits at the time of enrollment.

Table 3. High School Academic Information $(N=390)$

\begin{tabular}{lll}
\hline Characteristics & N & \% \\
\hline High School Grade Point Average & & \\
$2.00-2.50$ & 12 & 3.1 \\
$2.51-3.00$ & 99 & 25.4 \\
$3.01-3.50$ & 111 & 28.5 \\
$3.51-4.00$ & 128 & 32.8 \\
Missing & 40 & 10.3 \\
ACT Composite Score & & \\
$12-19$ & 25 & \\
$20-21$ & 59 & 6.4 \\
$22-23$ & 84 & 15.2 \\
$24-25$ & 62 & 21.5 \\
$26-27$ & 37 & 15.9 \\
$28-33$ & 43 & 9.5 \\
Missing & 80 & 11.0 \\
ACT Math Score & & 20.5 \\
$16-19$ & 35 & \\
$20-21$ & 45 & 9.0 \\
$22-23$ & 50 & 11.6 \\
$24-25$ & 68 & 12.8 \\
$26-27$ & 43 & 17.4 \\
$28-33$ & 49 & 11.0 \\
Missing & 100 & 12.6 \\
ACT Verbal Score & & 25.6 \\
$10-19$ & 73 & \\
$20-21$ & 62 & 18.7 \\
$22-23$ & 51 & 15.9 \\
$24-25$ & 44 & 13.1 \\
$26-27$ & 25 & 11.3 \\
$28-33$ & 35 & 6.4 \\
Missing & 100 & 9.0 \\
Admitted Credit Hours & & 25.6 \\
0 & & \\
$1-10$ & & 56.7 \\
$11-20$ & & 25.4 \\
\hline & & 10.2 \\
\hline
\end{tabular}


Family background characteristics are represented in Table 4. Family background characteristics include region of residence prior to college, both mother and father education levels and adjusted gross family income. The regions of residents are broken down according to the United States Census Bureau. The majority (55.4) of the students come from the Midwest. The second largest region represented by this sample is the West with 118 students $(30.3 \%)$. The Northeast accounts for 24 students $(6.2 \%)$, the South for 19 students (4.9\%) and other accounts for 13 students (3.4\%). Father's education level indicates that $193(49.5 \%)$ had a college education, while $94(24.1 \%)$ had a high school education and nine $(2.3 \%)$ had an elementary school education. Mother's education level indicates that $208(53.3 \%)$ had a college education, while $86(22.1 \%)$ had a high school education. The missing records for father's and mother's education level were $94(24.1 \%)$ and $96(24.6 \%)$ respectively. The parental adjusted gross income ranged from a negative $\$ 39,611$ to $\$ 767,182$ with a mean of $\$ 92,412$ and a standard deviation of 82,123 . The parental adjusted gross income data was missing from $83(21.3 \%)$ records.

Table 4. Family Background Information $(N=390)$

\begin{tabular}{lll} 
Characteristics & N & \% \\
\hline Region of Residence & & \\
$\quad$ Midwest & 216 & 55.4 \\
West & 118 & 30.3 \\
South & 19 & 4.9 \\
Northeast & 24 & 6.2 \\
Other & 13 & 3.4 \\
& & \\
Father's Education Level & 9 & 2.3 \\
Elementary School & 94 & 24.1 \\
High School & 193 & 49.5 \\
College & 94 & 24.1 \\
Missing & & \\
Mother's Education Level & 0 & 0 \\
Elementary School & 86 & 22.1 \\
High School & 208 & 53.3 \\
College & 96 & 24.6 \\
Missing & & \\
Parental Adjusted Gross Income & & \\
<30,000 & 40 & 10.3 \\
30,000-60,000 & 63 & 16.2 \\
60,001-90,000 & 80 & 20.5 \\
$90,001-120,000$ & 57 & 14.6 \\
>120,000 & 67 & 17.2 \\
Missing & 83 & 21.9 \\
& & \\
\hline
\end{tabular}

As seen in Table 5, the retention rate after the first semester was $91.8 \%$, indicating that 358 of the 390 students remained enrolled at the university for the Spring semester. The retention rate between the first and second year of enrollment dropped to $82.6 \%$, indicating that 322 of the 390 students remained enrolled at the university after the first year. The overall retention rates between first and second year students for the university the 2006 and 2007 cohorts of first-time, full-time students was $75 \%$ and $78 \%$ respectively. Of the 390 students who initially enrolled as a flight major, $67.4 \%$ or 263 students remained 
as a flight major after the first year of enrollment. Of the remaining students, 20 (5.1\%) switched to the Air Traffic Control major, 6 (1.5\%) switched to airport management, $33(8.5 \%)$ remained enrolled at the initial university but switched out of the department of aviation, and 68 (17.4\%) left the university all together.

Table 5. Persistence Patterns (N=390)

\begin{tabular}{lll}
\hline Characteristics & $\mathbf{N}$ & \% \\
& & \\
Retention after the first semester & & 91.8 \\
Yes & 358 & 8.2 \\
No & 32 & \\
& & 82.6 \\
Retention after the first year & 322 & 17.4 \\
Yes & 68 & \\
No & & 67.4 \\
Declared major after first year & 263 & 5.1 \\
Flight & 20 & 1.5 \\
Air Traffic Control & 6 & 8.5 \\
Airport Management & 33 & 17.4 \\
Other (UND) & 68 & \\
Left UND & & \\
\end{tabular}

What is the relationship between a student's pre-entry attributes and persistence? Two dependent variables were assessed: enrollment at the initial institution during the second fall semester, and declared major (flight or non-flight) at the beginning of the second fall semester. Since this research question assesses the relationship between numerous pre-entry variables to a single dependent variable, multiple regression analysis was utilized as the primary statistical test.

The full model analysis determined that there was a relationship between pre-entry attributes and student persistence between the first and second year. As seen in Table 6, these independent pre-entry attributes accounted for $9.6 \%\left(\mathrm{R}=.310, \mathrm{R}^{2}=.096, \mathrm{~F}=1.705, d f=11,176, p=.076\right)$ of the variance in institutional persistence after the first year. High school grade point average had the most significant relationship with student persistence after the first year. 
Table 6. Beta Weights, $t$ Values, Significance of $t$, Correlation Coefficients and Significance of the Preentry Independent Factors with Second Fall Semester Enrollment for the Total Sample

\begin{tabular}{llllll}
\hline Factor & Beta & $\mathbf{t}$ & Sig. of $\mathbf{t}$ & Corr. & Sig. \\
\hline Gender & & & & & \\
Age & -.008 & -.102 & .919 & -.083 & .128 \\
High School GPA & .065 & .866 & .388 & .035 & .318 \\
ACT Composite & .297 & 3.433 & .001 & .243 & $<.001^{*}$ \\
ACT Math & -.035 & -.193 & .847 & .005 & .475 \\
ACT Verbal & -.032 & -.278 & .781 & .038 & .303 \\
Ethnicity & -.097 & -.675 & .501 & -.003 & .486 \\
Admitted Credit Hours & -.054 & -.738 & .461 & -.026 & .360 \\
Father's Education Level & .062 & .782 & .435 & .107 & .072 \\
Mother's Education Level & .107 & 1.390 & .166 & .102 & .083 \\
Adjusted Family Gross Income & .007 & .086 & .931 & .023 & .376 \\
Full Model R ${ }^{2}=.096$ & .075 & 1.009 & .314 & .042 & .281 \\
\hline * $p<.05$ & & & & & \\
\hline
\end{tabular}

Since this study is focusing on student enrollment in a professional flying degree, the same pre-entry attributes were studied in regards to maintaining the declared flight major between the first and second year of enrollment. The same regression analysis was conducted replacing enrollment in the second fall semester, with declared major (flight or non-flight) for the second fall semester. Table 7 lists the Beta weights for each factor, the $t$ values for the Beta weights, the significance of the $t$ values, the correlation coefficients of the independent variable with the dependent variable of declared major following the first year, and the significance of the correlation.

The full model analysis determined that there were no significant relationships between pre-entry attributes and declared major between the first and second year. These independent pre-entry attributes accounted for $7.4 \%\left(\mathrm{R}=.272, \mathrm{R}^{2}=.074, \mathrm{~F}=1.281, d f=11,176, p=.238\right)$ of the variance in declared major after the first year. Since no significance was found, no further analysis was completed between these two areas. 
Table 7. Beta Weights, $t$ Values, Significance of $t$, Correlation Coefficients and Significance of the Preentry Independent Factors with Declared Major Second Fall Semester Enrollment for the Total Sample

\begin{tabular}{llllll}
\hline Factor & Beta & $\mathbf{t}$ & Sig. of t & Corr. & Sig. \\
\hline Gender & -.024 & -.299 & .765 & -.040 & .292 \\
Age & .052 & .686 & .494 & .051 & .245 \\
High School GPA & .200 & 2.287 & .023 & .108 & .070 \\
ACT Composite & .047 & .258 & .797 & -.089 & .114 \\
ACT Math & -.080 & -.681 & .497 & -.050 & .249 \\
ACT Verbal & -.299 & -1.582 & .116 & -.112 & .063 \\
Ethnicity & -.077 & -1.042 & .299 & -.061 & .204 \\
Admitted Credit Hours & .044 & .552 & .582 & .028 & .353 \\
Father's Education Level & .059 & .763 & .446 & .065 & .188 \\
Mother's Education Level & .062 & .779 & .437 & .045 & .268 \\
Adjusted Family Gross Income & .126 & 1.677 & .095 & .086 & .120 \\
Full Model R ${ }^{2}=.074$ & & & & & \\
\hline
\end{tabular}

$* p<.05$

The first research question explored the relationship between pre-entry attributes and student persistence. Student persistence was defined as either enrollment at the university after the first year, as well as declared major (flight or non-flight) after the first year. The only significance was found between high school grade point average and enrollment after the first year.

What is the relationship between a student's pre-entry attributes and academic success as measured in grade point average? Since this research question is assessing the relationship between numerous preentry variables to a single dependent variable, multiple regression analysis was utilized as the primary statistical test. Fall grade point average was used as the dependent variable in regards to academic success.

The first analysis was conducted by placing all of the pre-entry factors into a full model regression simultaneously to determine the Beta weights for each factor, the $t$ values for the Beta weights, the significance of the $t$ values, the correlation coefficients of the independent variable with the dependent variable of Fall grade point average following the first year, and the significance of the correlation. Table 8 shows the results. 
Table 8. Beta Weights, $t$ Values, Significance of $t$, Correlation Coefficients and Significance of the Preentry Independent Factors with Fall Semester Grade Point Average for the Total Sample

\begin{tabular}{llllll}
\hline Factor & Beta & $\mathbf{t}$ & Sig. of t & Corr. & Sig. \\
\hline Gender & .114 & 1.670 & .097 & -.057 & .217 \\
Age & .148 & 2.273 & .024 & .091 & .107 \\
High School GPA & .545 & 7.275 & $<.001$ & .467 & $<.001^{*}$ \\
ACT Composite & -.231 & -1.490 & .138 & .112 & .063 \\
ACT Math & .047 & .465 & .643 & .155 & $.017^{*}$ \\
ACT Verbal & .067 & .544 & .587 & .129 & $.039^{*}$ \\
Ethnicity & -.025 & -.400 & .690 & .023 & .377 \\
Admitted Credit Hours & .078 & 1.147 & .253 & .185 & $.005^{*}$ \\
Father's Education Level & .134 & 2.026 & .044 & .172 & $.009^{*}$ \\
Mother's Education Level & .136 & 2.009 & .046 & .182 & $.006^{*}$ \\
Adjusted Family Gross Income & .117 & 1.821 & .070 & .082 & .131 \\
Full Model R ${ }^{2}=.323$ & & & & & \\
\hline a & & & & &
\end{tabular}

$* p<.05$

The full model analysis determined that there was a relationship between pre-entry attributes and student academic success. These independent pre-entry attributes accounted for $32.3 \%\left(\mathrm{R}=.568, \mathrm{R}^{2}=.323\right.$, $\mathrm{F}=7.624, d f=11,176, p<.001)$ of the variance in academic success after the first semester. High school grade point average had the most significant relationship to fall semester grade point average.

In utilizing the stepwise forward regression (see Table 9), high school grade point average was found to have a significant impact on the variance out of all the pre-entry attributes being studied. This was followed by the mother's education level, age at entry and father's education level. These four variables accounted for $28.6 \%$ of the variance $(F=18.366, d f=4,183, p=.000)$. 
Table 9. $R^{2}$ Change Results Based on Stepwise Forward Regression for the Pre-entry Independent Factors on Fall Semester Grade Point Average for the Total Sample

\begin{tabular}{lllll}
\hline Factor & $\mathbf{R}$ & $\mathbf{R}^{2}$ & $\mathbf{R}^{2}$ Chg. & Sig. Chg. \\
\hline High School GPA & .467 & .218 & .218 & .000 \\
Mother's Education Level & .499 & .249 & .031 & .006 \\
Age at Entry & .520 & .271 & .022 & .020 \\
Father's Education Level & .535 & .286 & .016 & .046 \\
$\begin{array}{l}\text { Factors not in equation: Gender, ACT Composite, ACT Math, ACT Verbal, Ethnicity, Admitted } \\
\text { Credit Hours, Adjusted Family Gross Income }\end{array}$ \\
\hline
\end{tabular}

\section{DISCUSSION AND CONCLUSION}

The only pre-entry attribute that had a significant relationship in predicting student enrollment after the first year was high school grade point average. It was determined that high school grade point average accounted for $5.9 \%$ of the variance in the stepwise forward regression model.

Persistence was also measured in relation to retaining students in the professional flight major. There were no significant findings in regards to pre-entry attributes and declared major (flight or non-flight) after the first year. This indicates that when persistence is studied from a program standpoint versus an institutional approach the pre-entry variables do little in predicting student persistence. These findings would suggest that admission policies and program specific policies should more greatly favor a student's high school grade point average, over standardized test scores. It seems that high school academic achievement is a better measure of a student's overall college academic performance and motivation than the test scores.

The lack of statistically significant pre-entry attribute variables that can assist in predicting student persistence in this sample of students may be another area of further research. Since this sample population consisted of students who entered into the university with the same initial major (professional flight) declared, a major that has a high cost associated with completing the degree requirements, perhaps students with similar backgrounds self-selected into this program. That would explain the lack of significance in the pre-entry attributes in their ability to predict persistence patterns both for remaining enrolled in the university as well as in the specific flight major. Further research should examine student pre-entry attributes for other specific majors in order to more fully understand student persistence patterns and the differences that may exist between academic majors.

There was a relationship with numerous significant variables to predict student academic achievement based on the pre-entry attributes. The significant variables relating to Fall semester academic achievement included high school grade point average, mother's education level, age at entry and father's 
education level. These variables accounted for $28.6 \%$ of the variance in the stepwise forward regression model.

These results indicate that a student's background, both in the sense of high school academic achievement as well as parental education level, influences how well a student will perform during their first year of college academically. Parental education levels and incomes are variables typically included as a measure in socio-economic status. Since this sample consists of students with only one declared major, further analysis and research should be conducted that would compare the parental education levels for various groups of students with similarly declared majors to see patterns and similarities exist. Since the major analyzed in this study is a high cost degree, one may expect the parental education attainment to be higher in order to afford the more costly program.

It is important to note that more pre-entry variables were significant in predicting academic success than were found significant in predicting student persistence. This is just further evidence that the student persistence puzzle is more complex, and less fully understood. By empirically testing and analyzing the various components of Tinto's (1993) theory of student departure, one by one the pieces of this complex puzzle can be put into place. Through enough research and discussion about student persistence taking place in universities and specifically in aviation programs, the student persistence puzzle will take shape. Through implementing new ideas and initiatives more students will successfully persist in their aviation studies and graduate. 


\section{REFERENCES}

Allen, D. (1999). Desire to finish college: An empirical link between motivation and persistence. Research in Higher Education, 40(4), 461-485.

Bean, J. P. (1980) Dropouts and turnover: The synthesis and test of a causal model of student attrition. Research in Higher Education, 12(2), 155-187.

Beckman, W. S., \& Barber, P. M. (2008). Factors impacting student retention in a university professional pilot program. International Journal of Applied Aviation Studies, 7(2), 295-310.

Berenson, M. L, Levine, D. M., \& Krehbiel, T.C. (2002). Business statistics: Concepts and application. (8th ed.). Upper Saddle River, NJ: Prentice-Hall.

Berger, J., \& Milem, J. (1999). The role of student involvement and perceptions of integration in a casual model of student persistence. Research in Higher Education. 40, 641-664.

Braxton, J. (Ed.) (2000). Reworking the student departure puzzle. Nashville, TN: Vanderbilt University Press.

Braxton, J., Milem, J., \& Sullivan, A. (2000). The influence of active learning on the college student departure process: Toward a revision of Tinto's theory. Journal of Higher Education, 71, 569-590.

Caison, A. (2007). Analysis of institutionally specific retention research: A comparison between survey and institutional database methods. Research in Higher Education, 48, 435-451.

Durkheim, E. (1951). Suicide: A study in sociology. Translated by J. A. Spaulding and G. Simpson. New York: The Free Press.

Elkins, S. Braxton, J., \& James, G. (2000). Tinto's separation stage and its influence on first semester college student persistence. Research in Higher Education. 41, 251-268.

Federal Aviation Administration. (2007). 2007 U.S. Civil Airmen Certificates. Retrieved July 9, 2008, from http://www.faa.gov/data_statistics/aviation_data_statistics/civil_airmen_statistics/2007/

Herzog, S. (2005). Measuring determinants of student return vs. dropout/stopout vs. transfer: A first-tosecond year analysis of new freshman. Research in Higher Education, 46(8), 883-928.

Kahn, J., \& Nauta, M. (2001). Social-cognitive predictors of first-year college student persistence: The importance of proximal assessment. Research in Higher Education, 42(6), 633-652.

Leuwerke, W., Robbins, S., Sawyer, R., \& Hovland, M. (2004). Predicting engineering major status from mathematics achievement and interest congruence. Journal of Career Assessment, 12(2), 135149.

Luedtke, J., \& Papazafiropoulos, I. (1996). Retention in collegiate aviation. Journal of Air Transportation World Wide, 1(1), 39-50. 
Maggio, J., White, W., Molstad, S., \& Kher, N. (2005). Pre-freshman summer programs' impact on student achievement and retention. Journal of Developmental Education, 29, 2-8.

Mertler, C. A., \& Vannatta, R. A. (2005). Advanced and multivariate statistical methods: Practical application and interpretation. (3rd. ed.). Glendale, CA: Pyrczak Publishing.

Metz, G. (2004-2005). Challenges and changes to Tinto's persistence theory: A historical review. Journal of College Student Retention, 6(2), 191-207.

Murtaugh, P. A., Burns, L. D., \& Schuster, J. (1999). Predicting the retention of university students. Research in Higher Education, 40(3), 355-371.

Ott, J. (2006, May 22). Pilot shortfall: Training school enrollment rises, but study suggests more needed to meet future demand. Aviation Week \& Space Technology, 51-54.

Pantages, T., \& Creedon, C. (1978). Studies of college attrition: 1950-1975. Review of Educational Research, 48(1), 49-101.

Pascarela, E. T., \& Terenzini, P. T. (1980). Predicting freshman persistence and voluntary dropout decisions from theoretical models. Journal of Higher Education, 51(1), 60-75.

Pascarela, E. T., \& Terenzini, P. T. (1991). How college affects students: Findings and insights from twenty years of research. San Francisco, CA: Jossey-Bass Publishers.

Pascarela, E. T., \& Terenzini, P. T. (2005). How college affects students: A third decade of research. San Francisco, CA: Jossey-Bass Publishers.

Spady, W. G. (1970). Dropouts from higher education: An interdisciplinary review and synthesis. Interchange, 1, 64-85.

St. John, E. P., Hu, S., Simmons, A. B., \& Musoba, G. D. (2001). Aptitude vs. merit: What matters in persistence. The Review of Higher Education, 24(2), 131-152.

Strauss, L., \& Volkwein, J. F. (2004). Predictors of student commitment at two-year and four-year institutions. The Journal of Higher Education, 75(2), 203-227.

Szafran, R. (2001). The effect of academic load on success for new college students: Is lighter better? Research in Higher Education, 42(1), 27-50.

Tinto, V. (1975). Dropout from higher education: A theoretical synthesis of recent research. Review of Educational Research, 45, 89-125.

Tinto, V. (1993). Leaving college: Rethinking the causes and cures of student attrition. Chicago, IL: University of Chicago Press. 
Tinto, V. (1998). Colleges as communities: Taking research on student persistence seriously. The Review of Higher Education, 21(2), 167-177.

Titus, M. A. (2004). An examination of the influence of institutional context on student persistence at 4-year colleges and universities: A multilevel approach. Research in Higher Education, 45(7), 673-699.

Trochim, W. M. (2005). Research methods: A concise knowledge base. Mason, OH: Thompson.

United States Census Bureau. (2007). Income Statistics. Retrieved September 14, 2008, from http://www.census.gov/hhes/www/income/income.html

Van Gennep, A. (1960). The Rites of Passage. Translated by M. Vizedom and G. Caffee. Chicago: University of Chicago Press.

Zhang, G., Anderson, T., Ohland, M., Carter, R., \& Thorndyke. B. (2002). Identifying factors influencing engineering student graduation and retention: A longitudinal and cross-institutional study. Proc. Amer. Soc. Eng. Ed Southeast., Gainesville, FL, April 2002, Session 2793. 